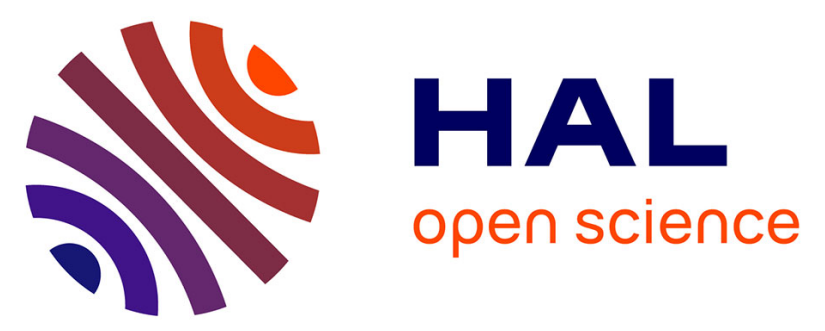

\title{
Endometriosis with infertility: a comprehensive review on the role of immune deregulation and immunomodulation therapy
}

Kamila Kolanska, Jaume Alijotas-reig, Jonathan Cohen, Meryem Cheloufi, Lise Selleret, Emmanuelle D'argent, Gilles Kayem, Enrique Esteve Valverde, Olivier Fain, Marie Bornes, et al.

\section{To cite this version:}

Kamila Kolanska, Jaume Alijotas-reig, Jonathan Cohen, Meryem Cheloufi, Lise Selleret, et al.. Endometriosis with infertility: a comprehensive review on the role of immune deregulation and immunomodulation therapy. American Journal of Reproductive Immunology, 2020, 10.1111/aji.13384 . hal-03047932

\section{HAL Id: hal-03047932 \\ https://hal.sorbonne-universite.fr/hal-03047932}

Submitted on 9 Dec 2020

HAL is a multi-disciplinary open access archive for the deposit and dissemination of scientific research documents, whether they are published or not. The documents may come from teaching and research institutions in France or abroad, or from public or private research centers.
L'archive ouverte pluridisciplinaire HAL, est destinée au dépôt et à la diffusion de documents scientifiques de niveau recherche, publiés ou non, émanant des établissements d'enseignement et de recherche français ou étrangers, des laboratoires publics ou privés. 
Endometriosis with infertility: a comprehensive review on the role of immune deregulation and immunomodulation therapy

Kamila Kolanska (1), Jaume Alijotas-Reig (2), Jonathan Cohen (1), Meryem Cheloufi (3), Lise Selleret (1), Emmanuelle d'Argent (1), Gilles Kayem (3), Enrique Esteve Valverde (2), Olivier Fain (4), Marie Bornes (1), Emile Darai (1), Arsene Mekinian (6)

1Sorbonne Université, AP-HP, Hôpital Tenon, service de Gynécologie-Obstétrique et Médecine de la Reproduction, Université Paris 06, UMRS-938, F-75020, Paris, France. GRC-6 Centre Expert En Endométriose (C3E), Sorbonne Université, UMRS938.

${ }^{2}$ Department of Internal Medicine. Sant Joan de Deu Hospital, Althaia Healthcare University Network of Manresa, Barcelona (Catalonia). Spain.

3Sorbonne Université, AP-HP, Hôpital Trousseau, service d'Obstétrique, Université Paris 06, F-75012, Paris, France

4Sorbonne Université, AP-HP, Hôpital Saint-Antoine, service de Médecine Interne and Inflammation- (DMU i3), F-75012, Paris, France

Corresponding authors: arsene.mekinian@aphp.fr

Sorbonne Université, AP-HP, Hôpital Saint-Antoine, service de Médecine Interne and Inflammation- (DMU i3), F-75012, Paris, France

Key words: endometriosis; infertility; immune dysregulation; TNF $\alpha$ antagonists 


\section{ABSTRACT: \\ Background}

Endometriosis is a multifactorial pathology dependent on intrinsic and extrinsic factors, but the immune deregulation seems to play a pivotal role. In endometriosis-associated infertility this could raise the benefit of immunomodulatory strategies to improve the results of ART. In this review, we will describe (1) sera and peritoneal fluid cytokines and immune markers; (2) autoantibodies; (3) immunomodulatory treatments in endometriosis with infertility.

\section{Methods}

The literature research was conducted in Medline, Embase and Cochrane Library with keywords: "endometriosis", "unexplained miscarriage", "implantation failure", "recurrent implantation failure » and « IVF-ICSI », « biomarkers of autoimmunity", “TNF- $\alpha$ ", “TNF- $\alpha$ antagonists", “infliximab", “adalimumab", "etanercept", “immunomodulatory treatment", “steroids", "intralipids", “intravenous immunoglobulins”, "G-CSF”, "pentoxyfylline”.

\section{Results}

Several studies analyzed the levels of pro-inflammatory cytokines in sera and peritoneal fluid of endometriosis-associated infertility, in particular TNF- $\alpha$. Various autoantibodies have been found in peritoneal fluid and sera of infertile endometriosis women even in the absence of clinically defined autoimmune disease, as antinuclear, anti-SSA and antiphospholipid autoantibodies. In few uncontrolled studies, steroids and TNF- $\alpha$ antagonists could increase the pregnancy rates in endometriosis-associated infertility, but well-designed trials are lacking.

\section{Conclusion}

Endometriosis is characterized by increased levels of cytokines and autoantibodies. This suggests the role of inflammation and immune cell deregulation in infertility associated to endometriosis. The strategies of immunomodulation to regulate these immune deregulations are poorly studied and well-designed studies are necessary. 


\section{Introduction}

Endometriosis is an inflammatory oestrogen-dependent chronic disease defined by the presence of endometrial glands and stroma at extra-uterine sites [1]. The prevalence vary from $5-10 \%$ in women with pain symptoms, dyspareunia and dysmenorrhea, and at least one third of them suffer from infertility [2]. Besides chronic pain representing an important challenge in these young women, another important problem is the management of endometriosisassociated infertility. Reduced fertility in women with endometriosis can be related to mechanical distortions with pelvic adhesions, occlusions of the tubal ostia and decreased folliculogenesis. Chronic intraperitoneal inflammation is another important feature of endometriosis and can impair the fertility by increasing the concentration of pro-inflammatory cytokines. This pro-inflammatory environment can interfere with oocyte-sperm interactions, embryo development and implantation [3]. Moreover, increased prevalence of various autoantibodies and autoimmune diseases such as systemic lupus erythematosus, Sjogren's syndrome, rheumatoid arthritis or chronic inflammatory bowel disease in endometriosis women raise the possible autoimmune link with endometriosis-associated infertility $[4,5]$. The physiopathological mechanism involved in endometriosis-associated infertility is not clearly elucidated. The hypothesis of altered oocyte quality is frequently raised, as the pregnancy rates in egg donation tend to be decreased if the donor has the history of endometriosis $[6,7]$. On the other hand the endometrial alterations involved in embryo implantation process in women with endometriosis are debatable [8,9]. Nevertheless, the immune profile alteration observed in women with endometriosis could play an important role in the infertility.

As far as medical management of endometriosis is concerned, the handling of chronic pain is mainly based on hormonal therapies, such as contraceptive pill, progestogens, GnRH agonists and anti-aromatase inhibitors. These therapies, however, are inconvenient for the management of infertility. The management of endometriosis-associated infertility combine the selective surgery and the Assisted Reproductive Technology (ART). The place of immunomodulatory therapies has been raised for the endometriosis-associated infertility but remain poorly studied [10]. Among the potential immunomodulatory therapies, the value of steroids and TNF- $\alpha$ antagonists have been previously studied, but their potential efficacy remains to be 
determined in well-designed studies [11]. Even if the use of assisted reproductive technologies (ART) in endometriosis-associated infertility increases the pregnancy rates, effective combined strategies to improve the results of ART in endometriosis-associated infertility are still lacking.

The aim of this review is to describe sera and peritoneal fluid cytokines, autoantibodies and immunomodulatory treatments in endometriosis-associated infertility.

\section{Methods}

\section{Search strategy}

Data for this review were obtained through a systematic and comprehensive literature search using the keywords to identify articles published in English from PubMed (MEDLINE), Embase and Cochrane Library and limited to studies published in French or English between 1990 and 2020. Selection criteria included randomized clinical trials, observational openlabelled studies, case-reports and retrospective case-series related to endometriosis-associated infertility. The "Mesh Database" of Pubmed helped steer the search by combining Mesh keywords: "endometriosis", "unexplained miscarriage", "implantation failure", "recurrent implantation failure" and "IVF-ICSI", "biomarkers of autoimmunity", "TNF- $\alpha$ ", "cytokines", "TNF- $\alpha$ antagonists", “infliximab", “adalimumab”, "etanercept”, “immunomodulatory treatment", "steroids", “intralipids", “intravenous immunoglobulins", "hydroxychloroquine”, "G-CSF"; pentoxifylline". Research was carried out with the following keywords in the title, abstract or keywords in articles. A first selection was made by eliminating redundant articles and in this case, the most recent publication was taken into account.

\section{Cytokines and other immune factors in sera and peritoneal fluid of endometriosis- associated infertility: possible biomarkers}

Several studies analyzed the levels of pro-inflammatory cytokines in sera and peritoneal fluid of endometriosis-associated infertility $[12,13]$ [14]. Increased levels in peritoneal fluids of TNF- $\alpha$, interleukin-1 (IL)-1, IL-6, IL-10, TGF- $\beta 1$ and IL-8 were demonstrated in infertile women with endometriosis [15]. In comparison to women with tubal infertility, women with endometriosis-associated infertility have increased follicular fluid levels of TNF- $\alpha$, granulocyte-macrophage-colony stimulating factor (GM-CSF) and IL-15, whereas IL-10 
levels were significantly decreased [16]. Whereas IL-6 follicular fluid levels were not significantly increased in women with endometriosis-associated infertility [16], endometrial stromal cells from endometriosis implants secreted significantly higher levels of IL-6 at baseline and after IL-1 stimulation than cells from endometrium of women with endometriosis and normal controls [17].

The exact role of IL-1 and IL-6 in infertility is not completely elucidated. IL-6 promotes the acute phase of inflammatory response by inducing the differentiation of $\mathrm{B}$ and cytotoxic $\mathrm{T}$ cells and reducing the NK cell cytotoxic activity [18]. High concentrations of IL-6 might inhibit the proliferation of endometrial stromal cells [19]. Although the presence of IL-6 is required for the promotion of blastocyst development, its might limit the blastocyst interaction with matrix substrates during the process of adhesion [20]. On the other hand, IL-6 could reduce significantly the motility of sperm [21]. Interleukin-6 is involved in various pathologies of pregnancy such as miscarriage, preeclampsia or preterm birth [20]. As far as IL-1 is concerned, its role in disrupting of the endometrial decidualisation has been demonstrated [22]. IL-1 $\beta$ seems to inhibit estrogen receptor- $\alpha$ and progesterone receptors thus modifying hormonally induced signalization pathways [23].

Among women undergoing laparoscopy for pain, infertility or tubal ligation, serum and peritoneal fluid TNF- $\alpha$ and IL-6 levels were significantly increased in women with final diagnosis of endometriosis [24]. In in vitro studies TNF- $\alpha$ increases the transcriptional activity in endometrial epithelial cells and modulates the expression of estrogen-regulated genes, which are implicated in growth, proliferation and tissue invasion [25]. Higher peritoneal fluid IL-8 levels were induced by exposure to TNF- $\alpha$ [26]. Basal synthesis of TNF- $\alpha$, IL-6, and IL-8 and the LPS-stimulated synthesis of TNF- $\alpha$ by blood monocytes from women with endometriosis was significantly greater in comparison to fertile controls, whereas no changes were noted for IL-10 [27].

It is not well established if those cytokine local and general changes are the reason or the consequence of endometriosis. Nevertheless, the presence of ectopic endometrium promotes a highly inflammatory, pro-angiogenic and hormone-rich microenvironment [28].These increased cytokines may be secreted by peritoneal macrophages, lymphocytes, endometrial implants and mesothelial cells of the peritoneum which are recruited and activated in 
endometriosis [15] [29]. The consequence of increased proinflammatory cytokine levels in peritoneal fluid could result in diminished quality of oocyte and, consequently, embryos, even if the precise mechanisms are not established [14] [28]. The impaired adhesion, implantation and angiogenesis are among the various mechanisms implicated in the endometriosisassociated infertility, an increased inflammatory status is probably one of the corner mechanism for the decreased fertility in endometriosis [15] [14].

Proangiogenic factors such as VEGF and PIGF have been proposed as the principal molecules involved in the neovascularization necessary for the implantation, establishment and development of ectopic endometriotic tissue [30] [31]. The role of PIGF in the induction of inflammation has been suggested in cutaneous inflammation [32]. Their concentrations were found to be increased in peritoneal fluid of women with endometriosis, as well as that of IL-8 which is a potent chemo-attractant for numerous immune cells [33] [34].

Other factors such as antioxidant agents, chemokines, adhesion molecules (sICAM-1) and chemotactic proteins such as monocyte chemoattractant protein-1(MCP-1), regulated upon activation, normal T cell (RANTES or CCL5) could be impaired in endometriosis-associated infertility [33] [34] [35]. Even if the levels of these various cytokines and factors could be dysregulated in endometriosis, the cytokines measurement in peritoneal fluid and serum is not actually used in routine screening to demonstrate the underlying inflammation and determine women that could benefit from immunomodulation strategies. Many biomarkers for endometriosis have been investigated, but no biomarker has been validated and a panel of biomarkers will most likely be necessary for a complex disease such as endometriosis. [36]

\section{Prevalence of autoantibodies in endometriosis-associated infertility}

Various autoantibodies have been found in peritoneal fluid and sera of infertile endometriosis women even in the absence of clinically defined autoimmune disease [12]. Antinuclear (ANA), anti-SSA/Ro and antiphospholipid autoantibodies (aPL) were more frequent in women with endometriosis than controls [37]. Anti-cardiolipin antibodies and anti-sperm antibodies were both more frequent in sera and peritoneal fluids of 323 various stage endometriosis women comparatively to infertile non-endometriosis patients [38].

Even if the exact mechanism of autoimmunity in infertility is not completely elucidated, its role in pregnancy loss has been widely accepted. aPL might be responsible for the damage of 
the trophoblast and provoke premature aging and necrosis of the villi [39] [40]. The presence of aPL could be associated to a lower ovarian reserve [41]. The ANA, on the other hand, could impact the embryo development as the development of murine embryos is blocked while incubating with ANA [42].A recent systematic review shows that the presence of ANA could be correlated to poorer IVF outcomes [43].

Laminins are an important and biologically active part of the basal lamina, influencing cell differentiation, migration, adhesion as well as phenotype and cell survival. In addition, laminins enhance trophoblast adhesion in the peri-implantation period, and anti-laminin-1 autoantibodies have been evaluated in endometriosis women. Both levels and prevalence of these autoantibodies were increased in endometriosis-associated infertility, even if their presence was not predictive of IVF failure [44, 45]. Anti-ovary, anti-theca, anti-granulosa cells and anti-endometrium autoantibodies have been also more prevalent in infertile women with endometriosis although their pathogenic and clinical value are uncertain [46]. Those autoantibodies may target ooplasm, zona pellucida and granulosa cells and alter the ovarian reserve and the IVF outcomes [40] [47]. Among 23 women with endometriosis-associated infertility, aPL, ANA antibodies were significantly more frequent than in infertile controls, except for lupus anticoagulant (LAC) and anti-thyroid antibodies [48]. Among 35 IVF cycles with at least one autoantibodies, $8(23 \%)$ women became pregnant, versus $16(46 \%)$ in autoantibodies-negative ones $(\mathrm{p}=0.04)$ [49]. Anti-GM-CSF antibodies levels were evaluated in 106 sera of endometriosis women and were significantly increased in patients with endometriosis compared to controls and were associated with the severity of the disease [50]. Despite the increased prevalence of these various autoantibodies, the predictive value of these autoantibodies on the issue of IVF remain to be determined.

\section{Immunomodulatory therapies}

\section{Steroids}

In a murine embryo assay, the addition of dexamethasone to murine embryo culture with endometriotic peritoneal fluid improved the rates of blastocyst development [51]. Few studies evaluated the benefit of steroids for endometriosis-associated infertility. Twenty-one patients with endometriosis received steroids before IVF, at $10 \mathrm{mg}$ /day from the $3^{\text {rd }}$ day of the cycle until the day of oocyte retrieval and the dosage was increased to $60 \mathrm{mg} /$ day from the evening 
of oocyte retrieval and for 4 days [52]. The rates of clinical pregnancies after IVF were compared to 44 controls with IVF without steroids. The clinical pregnancies rates were at $42.6 \%$ in the steroid treated group vs. $22.8 \%$ in the absence of steroid therapy $(p<0.05)$, without differences in the miscarriage rates. In women with positives autoantibodies the clinical pregnancy rates were higher in steroid treated group as compared to non-treated group (40.9\% vs $14.8 \% ; \mathrm{p}<0.05)$. In 84 infertile women with endometriosis, steroids were added during the entire IVF cycle or 5 days before embryo transfer and various autoantibodies were tested before IVF cycle [49]. In 35 autoantibodies-positives patients, steroid use during IVF cycle was associated with clinical pregnancy in $8 / 10$ cases versus $0 / 25$ in those without steroid treatment $(80 \%$ vs $0 \% \mathrm{p}<0.05)$. In 35 autoantibody-negative patients, pregnancy was obtained in $7 / 15$ cases with steroid treatment during IVF versus $9 / 20$ in the group without steroid treatment $(46.7 \%$ vs $45 \%, p=N S)$ [49]. No randomized trial is available to confirm the potential benefit of steroid treatment in these women.

\section{TNF- $\alpha$ antagonists}

Several studies showed an abnormal inflammation status in women with endometriosis and demonstrated increased levels of various pro-inflammatory cytokines, such as TNF- $\alpha$, IL-6, TGF- $\beta$ and IL-1 $\beta$, in sera and peritoneal fluids as has previously been mentioned [16]. TNF- $\alpha$ is usually expressed by human oocytes, corpus luteum and it is present in the follicular fluid [16]. In a baboon model of endometriosis, the neutralization of TNF- $\alpha$ activity with recombinant TNFRSF1A (the soluble form of TNF receptor type 1) significantly decreased the endometriotic lesions without causing the hypoestrogenic effects [12] [53] [54] [55]. Monoclonal anti-TNF- $\alpha$ in endometriosis baboons also reduced significantly the induced peritoneal endometriosis [56]. In a model of murine embryos cultured with different concentrations of TNF- $\alpha$, the blastocyst development ratio was significantly decreased in the presence of TNF- $\alpha$. The increased apoptosis and embryotoxicity of TNF- $\alpha$ was abrogated by the addition of adalimumab, a human monoclonal anti-TNF- $\alpha$ antibody [57]. In a randomized placebo-controlled blinded study using rat endometriosis model, female rats were randomized to receive either etanercept $0.4 \mathrm{mg} / \mathrm{kg}$ etanercept sc once weekly during 4 weeks or placebo [58]. The volume and extension of endometrial implants were significantly reduced in female rats under etanercept in comparison to untreated controls, but the effect on the clinical pregnancy was not analyzed in this study. 
A randomized trial analyzed the efficacy of infliximab versus placebo in 21 patients with endometriosis and chronic pelvic pain prior to surgery [59]. The decrease of pain severity was noted in $30 \%$ of infliximab treated women and was similar to those under placebo. The volume of endometriotic nodules, the lesions extension evaluated during the surgery and the extent of endometriosis were not significantly changed after infliximab use in comparison to placebo. The impact on the infertility was not analyzed in this trial.

So far no well-designed studies evaluated the clinical value of TNF- $\alpha$ antagonists in women with endometriosis-associated infertility. In a woman with severe endometriosis under etanercept for rheumatoid arthritis, no spontaneous pregnancy occurred, and she became pregnant several months later after IVF preceded by laparoscopic surgery [60]. The analysis of NK cell activity in a woman with extensive endometriosis and fifteen failed IVF and oocyte donation cycles showed increased NK cell activity before subsequent IVF. She received four doses of etanercept twice a week 6 month, which resulted in a successful birth [61]. Nineteen women with endometrioma received etanercept $50 \mathrm{mg}$ on the second day of the menstrual cycle preceding IVF cycle. The clinical pregnancy rate was higher in patients who received etanercept as compared to non-treated women, with odd ratio 4.17 [95\% CI $1.23-14.14)[62]$.

Data about the safety of TNF- $\alpha$ antagonists during the pregnancy are extensively reported, in particular in women with Crohn's disease and rheumatoid arthritis [11]. The main concern is the increased risk of infectious adverse events. In the only trial of infliximab in 21 women with endometriosis, an acute tonsillitis and a mild infusion reaction were noted [59]. From the actually available data, we can conclude that TNF- $\alpha$ blockers can be safely used during the implantation period and pregnancy [63]

\section{Intralipids}

Increased NK cells rates and cytotoxicity have been demonstrated in endometriosis-associated infertility, and in vitro and clinical studies raise the potential interest to use intravenous intralipid infusion to modulate the NK cells cytotoxicity in infertility $[64,65][15]$. The data about the use of intralipids in endometriosis-associated infertility report 3 women with increased uterine NK ( $\mathrm{uNK}$ ) which received intralipid infusion on the day of the embryo transfer in frozen embryo transfer cycles, 2nd infusion after the positive pregnancy test and 
following infusions every 2 weeks until 12th week of pregnancy which resulted in live birth in 2 cases [66]. However, uNK cells are necessary to achieve a normal implantation and further correct placentation. Like this, only cases with high uNK cells in endometrial fluid could be suitable for a treatments directed to reduce them. Thus, the role played for intralipids appears to be anecdotic.

\section{Antimalarials: Hydroxychloroquine}

Antimalarials particularly hydroxychloroquine (HCQ) exerts pleiotropic effects other than anti-infectious. Antimalarials have many anti-inflammatory, immune-regulatory and antiaggregant properties. Thus, they inhibit phospholipase activity, stabilize lysosomal membranes, block the production of several pro-inflammatory cytokines, impair complementdependent antigen-antibody reactions and attenuate antigen processing, and inhibit cellmediated cytotoxicity [67]. Besides, HCQ reduce the proliferative response of T-lymphocytes and NK cell activity [68]. In addition, inhibition of autophagy prevents immune activation of different cell types, which inhibits cytokine production and modulates CD154 expression on the surface of $\mathrm{T}$ cells. HCQ also inhibits macrophage TNF mRNA transcription and endotoxin-induced secretion of TNF- $\alpha$, IL-1, and IL-6 [69]. Studies of HCQ have yielded conflicting results in terms of the ability to inhibit TNF- $\alpha$, but HCQ blocks IL-1, IL-6, and IFN- $\gamma$ production by monocytes $[70,71]$. Furthermore, HCQ include anti-inflammatory properties through the blocking effect on the arachidonic acid cascade (phospholipases $A_{2}$ and C), which contribute to the down-regulation of pro-inflammatory prostaglandins.

Accordingly, the therapeutic effects of HCQ were assessed in an established mouse model of endometriosis [72]. HCQ significantly altered the endometriotic cells survival, by interfering with the inflammatory response, altering the organization of ectopic growth and modulating the expression of autophagic markers. Nevertheless, clinical data about the potential benefit of hydroxychloroquine are lacking.

\section{Other TNF- $\alpha$ inhibitor: Pentoxifylline}

Pentoxifylline is a phosphodiesterase inhibitor commonly used in the treatment of peripheral vascular disease. A wide range of immunomodulatory properties has been described, including of down-regulating TNF-alpha synthesis [73]. Furthermore, animal models showed a reduction in fetal resorption, thereby diminishing TNF-alpha and increasing IL-10 and IL-4 
placentally produced levels [74] [75]. Pentoxifylline has been used in cases of endometriosisrelated infertility [76] [77] [78]. It had been used years ago in the treatment of certain forms of thrombotic APS [79]. Given its capability to modify the Th1/Th2 cytokine balance together with its lack of adverse effects, pentoxifylline could be another useful drug to use in endometriosis. In nude mouse model with implanted human endometrial tissue from endometriosic women, the use of oral pentoxifylline reduced the number and the volume of endometriosis-like Lesions [80]. Recent Cochrane review included four trials involving 334 participants and pentoxifylline had no significant effect on reduction in pain. There was no evidence of an increase in clinical pregnancy events in the pentoxifylline group compared with placebo [81].

\section{Other immunomodulatory drugs}

Other immunomodulatory therapies have been used in unexplained recurrent implantation failure and unexplained recurrent miscarriages presumed to be in relation with the breaking of immune tolerance [11]. However, no data are currently available about G-CSF, intravenous immunoglobulins, classic immunosuppressive drugs or IL-2 low dose for the management of endometriosis-associated infertility. Other strategies, such as various stem cell therapies, are not actually evaluated in the women with infertility [82]. The increasing evidence of link between microbiota and uterine immunity could also discuss this possible immunomodulation strategy in the future [83].

\section{Conclusion}

Endometriosis is associated to a highly inflammatory, pro-angiogenic and hormone-rich microenvironment which may impair fertility by influencing oocyte and embryo quality, transport of gametes in the reproductive tract and embryo implantation by modifications in the eutopic endometrium. Even if the exact mechanisms of those changes remain unclear, the strategies of immunomodulation to regulate immune alterations involved in endometriosisassociated infertility have been proposed. The function of those therapies is still poorly studied and well-designed studies are necessary. 


\section{Co-authors contribution:}

Conception and design of the study: KK, AM, JAR, JC, MC, LS, EDA, GK, EEV, OF, MB, ED.

Acquisition of data: KK, AM, JAR

Analyze and interpretation of data: KK, AM, JAR

Drafting of the manuscript: KK, AM, JAR, JC, MC, LS, EDA, GK, EEV, OF, MB, ED.

Final approval: KK, AM, JAR, JC, MC, LS, EDA, GK, EEV, OF, MB, ED.

\section{Conflicts of interest:}

AM is investigator of CELGENE, ROCHE, CHUGAI founded trials with APHP and Hopital 15-20 promotion; AM received several fees for congress travels and experts' use from LFB, SANOFI, SHIRE, and CELGENE.

\section{Funding: none.}




\section{REFERENCES :}

1 Bulun SE. Endometriosis. The New England journal of medicine 2009;360(3): 268-79.

2 de Ziegler D, Borghese B, Chapron C. Endometriosis and infertility: pathophysiology and management. Lancet (London, England) 2010;376(9742):730-8.

3 Tanbo T, Fedorcsak P. Endometriosis-associated infertility: aspects of pathophysiological mechanisms and treatment options. Acta obstetricia et gynecologica Scandinavica 2017;96(6):659-67.

4 Lin YH, Yang YC, Chen SF, Hsu CY, Shen YC. Risk of systemic lupus erythematosus in patients with endometriosis: A nationwide population-based cohort study. Arch Gynecol Obstet 2020.

5 Shigesi N, Kvaskoff M, Kirtley $S$, et al. The association between endometriosis and autoimmune diseases: a systematic review and meta-analysis. Human reproduction update 2019;25(4):486-503.

6 Hauzman EE, Garcia-Velasco JA, Pellicer A. Oocyte donation and endometriosis: What are the lessons? Seminars in reproductive medicine 2013;31(2):173-7.

7 Katsoff B, Check JH, Davies E, Wilson C. Evaluation of the effect of endometriosis on oocyte quality and endometrial environment by comparison of donor and recipient outcomes following embryo transfer in a shared oocyte program. Clinical and experimental obstetrics \& gynecology 2006;33(4):201-2.

8 Lessey BA, Kim JJ. Endometrial receptivity in the eutopic endometrium of women with endometriosis: it is affected, and let me show you why. Fertility and sterility 2017;108(1):19-27.

9 Miravet-Valenciano J, Ruiz-Alonso M, Gómez E, Garcia-Velasco JA. Endometrial receptivity in eutopic endometrium in patients with endometriosis: it is not affected, and let me show you why. Fertility and sterility 2017;108(1):28-31.

10 Muñoz-Hernando $L$, Muñoz-Gonzalez $J L$, Marqueta-Marques $L$, et al. Endometriosis: alternative methods of medical treatment. International journal of women's health 2015; 7:595-603.

11 Mekinian A, Cohen J, Alijotas-Reig J, et al. Unexplained Recurrent Miscarriage and Recurrent Implantation Failure: Is There a Place for Immunomodulation? Am J Reprod Immunol 2016.

12 Tomassetti C, Meuleman C, Pexsters A, et al. Endometriosis, recurrent miscarriage and implantation failure: is there an immunological link? Reproductive biomedicine online 2006;13(1):58-64.

13 Kokcu A. Possible effects of endometriosis-related immune events on reproductive function. Arch Gynecol Obstet 2013;287(6):1225-33.

14 Halis G, Arici A. Endometriosis and inflammation in infertility. Annals of the New York Academy of Sciences 2004;1034:300-15.

15 Wu MY, Ho HN. The role of cytokines in endometriosis. Am J Reprod Immunol 2003;49(5):285-96.

16 Falconer H, Sundqvist J, Gemzell-Danielsson K, von Schoultz B, D'Hooghe TM, Fried G. IVF outcome in women with endometriosis in relation to tumour necrosis factor and anti-Müllerian hormone. Reproductive biomedicine online 2009;18(4):582-8.

17 Tseng JF, Ryan IP, Milam TD, et al. Interleukin-6 secretion in vitro is upregulated in ectopic and eutopic endometrial stromal cells from women with 
endometriosis. The Journal of clinical endocrinology and metabolism 1996;81(3): 1118-22.

18 Kang YJ, Jeung IC, Park A, et al. An increased level of IL-6 suppresses NK cell activity in peritoneal fluid of patients with endometriosis via regulation of SHP-2 expression. Human reproduction (Oxford, England) 2014;29(10):2176-89.

19 Zarmakoupis PN, Rier SE, Maroulis GB, Becker JL. Inhibition of human endometrial stromal cell proliferation by interleukin 6. Human reproduction (Oxford, England) 1995;10(9):2395-9.

20 Prins JR, Gomez-Lopez N, Robertson SA. Interleukin-6 in pregnancy and gestational disorders. J Reprod Immunol 2012;95(1-2):1-14.

21 Yoshida S, Harada T, Iwabe T, et al. A combination of interleukin-6 and its soluble receptor impairs sperm motility: implications in infertility associated with endometriosis. Human reproduction (Oxford, England) 2004;19(8):1821-5.

22 Frank GR, Brar AK, Jikihara H, Cedars MI, Handwerger S. Interleukin-1 beta and the endometrium: an inhibitor of stromal cell differentiation and possible autoregulator of decidualization in humans. Biology of reproduction 1995;52(1):184-91.

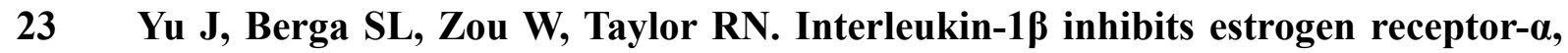
progesterone receptors $A$ and $B$ and biomarkers of human endometrial stromal cell differentiation: implications for endometriosis. Molecular human reproduction 2019;25(10):625-37.

24 Bedaiwy MA, Falcone T, Sharma RK, et al. Prediction of endometriosis with serum and peritoneal fluid markers: a prospective controlled trial. Human reproduction (Oxford, England) 2002;17(2):426-31.

25 Gori I, Pellegrini C, Staedler D, Russell R, Jan C, Canny GO. Tumor necrosis factor- $\alpha$ activates estrogen signaling pathways in endometrial epithelial cells via estrogen receptor $\alpha$. Molecular and cellular endocrinology 2011;345(1-2):27-37.

26 Arici A, Tazuke SI, Attar E, Kliman HJ, Olive DL. Interleukin-8 concentration in peritoneal fluid of patients with endometriosis and modulation of interleukin-8 expression in human mesothelial cells. Molecular human reproduction 1996;2(1):40-5.

27 Braun DP, Gebel H, House R, Rana N, Dmowski NP. Spontaneous and induced synthesis of cytokines by peripheral blood monocytes in patients with endometriosis. Fertility and sterility 1996;65(6):1125-9.

28 Miller JE, Ahn SH, Monsanto SP, Khalaj K, Koti M, Tayade C. Implications of immune dysfunction on endometriosis associated infertility. Oncotarget 2017;8(4): 7138-47.

29 Liang Y, Wu J, Wang W, Xie H, Yao S. Pro-endometriotic niche in endometriosis. Reproductive biomedicine online 2019;38(4):549-59.

30 Groothuis PG, Nap AW, Winterhager E, Grümmer R. Vascular development in endometriosis. Angiogenesis 2005;8(2):147-56.

31 Suzumori N, Sugiura-Ogasawara M, Katano K, Suzumori K. Women with endometriosis have increased levels of placental growth factor in the peritoneal fluid compared with women with cystadenomas. Human reproduction (Oxford, England) 2003;18(12):2595-8.

32 Oura H, Bertoncini J, Velasco P, Brown LF, Carmeliet P, Detmar M. A critical role of placental growth factor in the induction of inflammation and edema formation. Blood 2003;101(2):560-7. 
33 Arici A, Oral E, Attar E, Tazuke SI, Olive DL. Monocyte chemotactic protein-1 concentration in peritoneal fluid of women with endometriosis and its modulation of expression in mesothelial cells. Fertility and sterility 1997;67(6):1065-72.

34 Attar R, Attar E. Experimental treatments of endometriosis. Women's health (London, England) 2015;11(5):653-64.

35 Hornung D, Bentzien F, Wallwiener D, Kiesel L, Taylor RN. Chemokine bioactivity of RANTES in endometriotic and normal endometrial stromal cells and peritoneal fluid. Molecular human reproduction 2001;7(2):163-8.

36 O DF, Flores I, Waelkens E, D'Hooghe T. Noninvasive diagnosis of endometriosis: Review of current peripheral blood and endometrial biomarkers. Best practice \& research. Clinical obstetrics \& gynaecology 2018;50:72-83.

37 Taylor PV, Maloney MD, Campbell JM, et al. Autoreactivity in women with endometriosis. British journal of obstetrics and gynaecology 1991;98(7):680-4.

38 Ulcová-Gallová Z, Bouse V, Svábek L, Turek J, Rokyta Z. Endometriosis in reproductive immunology. Am J Reprod Immunol 2002;47(5):269-74.

39 Di Simone N, Meroni PL, de Papa N, et al. Antiphospholipid antibodies affect trophoblast gonadotropin secretion and invasiveness by binding directly and through adhered beta2-glycoprotein I. Arthritis and rheumatism 2000;43(1):140-50.

40 Carp HJ, Selmi C, Shoenfeld Y. The autoimmune bases of infertility and pregnancy loss. J Autoimmun 2012;38(2-3):J266-74.

41 Vega M, Barad DH, Yu Y, et al. Anti-mullerian hormone levels decline with the presence of antiphospholipid antibodies. Am J Reprod Immunol 2016;76(4):333-7.

42 Ying Y, Zhong YP, Zhou CQ, et al. Antinuclear antibodies predicts a poor IVFET outcome: impaired egg and embryo development and reduced pregnancy rate. Immunological investigations 2012;41(5):458-68.

43 Simopoulou M, Sfakianoudis K, Maziotis E, et al. The Impact of Autoantibodies on IVF Treatment and Outcome: A Systematic Review. International journal of molecular sciences 2019;20(4).

44 Caccavo D, Pellegrino NM, Totaro I, Vacca MP, Selvaggi L, Depalo R. Antilaminin-1 antibodies in sera and follicular fluid of women with endometriosis undergoing in vitro fertilization. International journal of immunopathology and pharmacology 2011;24(2):481-8.

45 Inagaki J, Hao $L$, Nakatsuka $M$, et al. A possible mechanism of autoimmunemediated infertility in women with endometriosis. Am J Reprod Immunol 2011;66(2): 90-9.

46 Mathur S, Peress MR, Williamson HO, et al. Autoimmunity to endometrium and ovary in endometriosis. Clinical and experimental immunology 1982;50(2):259-66.

47 Deroux A, Dumestre-Perard C, Dunand-Faure C, Bouillet L, Hoffmann P. Female Infertility and Serum Auto-antibodies: a Systematic Review. Clinical reviews in allergy \& immunology 2017;53(1):78-86.

48 Kaider AS, Kaider BD, Janowicz PB, Roussev RG. Immunodiagnostic evaluation in women with reproductive failure. Am J Reprod Immunol 1999;42(6):335-46.

49 Dmowski WP, Rana N, Michalowska J, Friberg J, Papierniak C, el-Roeiy A. The effect of endometriosis, its stage and activity, and of autoantibodies on in vitro fertilization and embryo transfer success rates. Fertility and sterility 1995;63(3):555-62. 
50 Toullec L, Batteux F, Santulli P, et al. High Levels of Anti-GM-CSF Antibodies in Deep Infiltrating Endometriosis. Reproductive sciences (Thousand Oaks, Calif.) 2020;27(1):211-7.

51 Heitmann RJ, Tobler KJ, Gillette L, Tercero J, Burney RO. Dexamethasone attenuates the embryotoxic effect of endometriotic peritoneal fluid in a murine model. Journal of assisted reproduction and genetics 2015;32(9):1317-23.

52 Kim CH, Chae HD, Kang BM, Chang YS, Mok JE. The immunotherapy during in vitro fertilization and embryo transfer cycles in infertile patients with endometriosis. The journal of obstetrics and gynaecology research 1997;23(5):463-70.

53 D'Antonio M, Martelli F, Peano S, Papoian R, Borrelli F. Ability of recombinant human TNF binding protein-1 (r-hTBP-1) to inhibit the development of experimentallyinduced endometriosis in rats. J Reprod Immunol 2000;48(2):81-98.

54 D'Hooghe TM, Nugent NP, Cuneo S, et al. Recombinant human TNFRSF1A (rhTBP1) inhibits the development of endometriosis in baboons: a prospective, randomized, placebo- and drug-controlled study. Biology of reproduction 2006;74(1): 131-6.

55 Barrier BF, Bates GW, Leland MM, Leach DA, Robinson RD, Propst AM. Efficacy of anti-tumor necrosis factor therapy in the treatment of spontaneous endometriosis in baboons. Fertility and sterility 2004;81 Suppl 1:775-9.

56 Falconer H, Mwenda JM, Chai DC, et al. Treatment with anti-TNF monoclonal antibody (c5N) reduces the extent of induced endometriosis in the baboon. Human reproduction (Oxford, England) 2006;21(7):1856-62.

57 Chen YJ, Wu HH, Liau WT, et al. A tumor necrosis factor- $\alpha$ inhibitor reduces the embryotoxic effects of endometriotic peritoneal fluid. Fertility and sterility 2013;100(5): 1476-85.

58 Islimye M, Kilic S, Zulfikaroglu E, Topcu O, Zergeroglu S, Batioglu S. Regression of endometrial autografts in a rat model of endometriosis treated with etanercept. European journal of obstetrics, gynecology, and reproductive biology 2011;159(1):184-9.

59 Koninckx PR, Craessaerts M, Timmerman D, Cornillie F, Kennedy S. Anti-TNFalpha treatment for deep endometriosis-associated pain: a randomized placebocontrolled trial. Human reproduction (Oxford, England) 2008;23(9):2017-23.

60 Shakiba K, Falcone T. Tumour necrosis factor-alpha blockers: potential limitations in the management of advanced endometriosis? A case report. Human reproduction (Oxford, England) 2006;21(9):2417-20.

61 Jerzak M, Niemiec T, Nowakowska A, Klochowicz M, Górski A, Baranowski W. First successful pregnancy after addition of enoxaparin to sildenafil and etanercept immunotherapy in woman with fifteen failed IVF cycles - case report. Am J Reprod Immunol 2010;64(2):93-6.

62 Önalan G, Tohma YA, Zeyneloğlu HB. Effect of Etanercept on the Success of Assisted Reproductive Technology in Patients with Endometrioma. Gynecologic and obstetric investigation 2018;83(4):358-64.

63 Alijotas-Reig J, Esteve-Valverde E, Ferrer-Oliveras R, Llurba E, Gris JM. Tumor Necrosis Factor-Alpha and Pregnancy: Focus on Biologics. An Updated and Comprehensive Review. Clinical reviews in allergy \& immunology 2017;53(1):40-53. 
64 Mekinian A, Cohen J, Alijotas-Reig J, et al. Unexplained Recurrent Miscarriage and Recurrent Implantation Failure: Is There a Place for Immunomodulation? Am J Reprod Immunol 2016;76(1):8-28.

65 Plaçais L, Kolanska K, Kraiem YB, et al. Intralipid therapy for unexplained recurrent miscarriage and implantation failure: Case-series and literature review. European journal of obstetrics, gynecology, and reproductive biology 2020;252:100-4.

66 Freitag N, Pour SJ, Fehm TN, et al. Are uterine natural killer and plasma cells in infertility patients associated with endometriosis, repeated implantation failure, or recurrent pregnancy loss? Arch Gynecol Obstet 2020.

67 Mekinian A, Costedoat-Chalumeau N, Masseau A, et al. Obstetrical APS: is there a place for hydroxychloroquine to improve the pregnancy outcome? Autoimmunity reviews 2015;14(1):23-9.

68 Ausiello CM, Barbieri P, Spagnoli GC, Ciompi ML, Casciani CU. In vivo effects of chloroquine treatment on spontaneous and interferon-induced natural killer activities in rheumatoid arthritis patients. Clin Exp Rheumatol 1986;4(3):255-9.

69 Karres I, Kremer JP, Dietl I, Steckholzer U, Jochum M, Ertel W. Chloroquine inhibits proinflammatory cytokine release into human whole blood. The American journal of physiology 1998;274(4):R1058-64.

70 Sperber K, Quraishi H, Kalb TH, Panja A, Stecher V, Mayer L. Selective regulation of cytokine secretion by hydroxychloroquine: inhibition of interleukin 1 alpha (IL-1-alpha) and IL-6 in human monocytes and T cells. J Rheumatol 1993;20(5):803-8.

71 van den Borne BE, Dijkmans BA, de Rooij HH, le Cessie S, Verweij CL. Chloroquine and hydroxychloroquine equally affect tumor necrosis factor-alpha, interleukin 6, and interferon-gamma production by peripheral blood mononuclear cells. J Rheumatol 1997;24(1):55-60.

72 Ruiz A, Rockfield S, Taran N, et al. Effect of hydroxychloroquine and characterization of autophagy in a mouse model of endometriosis. Cell death $\&$ disease 2016;7(1):e2059.

73 Ng SC, Gilman-Sachs A, Thaker P, Beaman KD, Beer AE, Kwak-Kim J. Expression of intracellular Th1 and Th2 cytokines in women with recurrent spontaneous abortion, implantation failures after IVF/ET or normal pregnancy. Am J Reprod Immunol 2002;48(2):77-86.

74 Chaouat G, Assal Meliani A, Martal J, et al. IL-10 prevents naturally occurring fetal loss in the CBA $x$ DBA/2 mating combination, and local defect in IL-10 production in this abortion-prone combination is corrected by in vivo injection of IFN-tau. Journal of immunology (Baltimore, Md. : 1950) 1995;154(9):4261-8.

75 Zhong XH, Shi WY, Ma AT, et al. Effects of Radix scutellariae and Rhizoma atractylodis on LPS-induced abortion and the uterine IL-10 contents in mice. The American journal of Chinese medicine 2008;36(1):141-8.

76 Shaw SM, Shah MK, Williams SG, Fildes JE. Immunological mechanisms of pentoxifylline in chronic heart failure. European journal of heart failure 2009;11(2): 113-8.

77 Lu D, Song H, Li Y, Clarke J, Shi G. Pentoxifylline for endometriosis. The Cochrane database of systematic reviews 2012;1:Cd007677.

78 Creus M, Fábregues F, Carmona F, del Pino M, Manau D, Balasch J. Combined laparoscopic surgery and pentoxifylline therapy for treatment of endometriosis- 
associated infertility: a preliminary trial. Human reproduction (Oxford, England) 2008;23(8):1910-6.

79 Bick RL. Antiphospholipid thrombosis syndromes. Clinical and applied thrombosis/hemostasis : official journal of the International Academy of Clinical and Applied Thrombosis/Hemostasis 2001;7(4):241-58.

80 Perelló M, González-Foruria I, Castillo P, et al. Oral Administration of Pentoxifylline Reduces Endometriosis-Like Lesions in a Nude Mouse Model. Reproductive sciences (Thousand Oaks, Calif.) 2017;24(6):911-8.

81 Lv D, Song H, Li Y, Clarke J, Shi G. Pentoxifylline versus medical therapies for subfertile women with endometriosis. The Cochrane database of systematic reviews 2009(3):Cd007677.

82 Pourakbari R, Ahmadi H, Yousefi M, Aghebati-Maleki L. Cell therapy in female infertility-related diseases: Emphasis on recurrent miscarriage and repeated implantation failure. Life sciences 2020;258:118181.

83 Agostinis C, Mangogna A, Bossi F, Ricci G, Kishore U, Bulla R. Uterine Immunity and Microbiota: A Shifting Paradigm. Frontiers in immunology 2019;10:2387. 